\title{
Hassán II: \\ Crónica de la muerte de un rey
}

\author{
Javier Ronda \\ Periodista, Canal Sur Radio
}

La muerte del rey Hassán II de Marruecos en el verano de 1999 fue una de las noticias mundiales con una repercusión social y política sin precedentes en la crónica periodística internacional. El anuncio del fallecimiento del monarca marroquí se produjo el 23 de julio por la tarde cuando la Agencia EFE se adelantaba a contar la noticia en España. La recepción de los canales de televisión y radio españoles en el norte de Marruecos permitió a los marroquíes que viven en esta zona del país conocer la noticia antes que en el resto del país magrebí.

\section{La muerte de un rey vecino}

T a noticia de la muerte del Rey Hassán II de Marruecos no es una información cualquiera. En el tranquilo verano del 99, la noticia se

producía un viernes por la tarde cuando en las redacciones de los medios de comunicación había numerosos periodistas que estaban de vacaciones estivales y los sufridos becarios se encargaban de revisar los teletipos y de aprender periodismo sobre el terreno.

Una vez que se confirmó la muerte del Rey, por la Casa Real de Marruecos en la noche del viernes, cuando el heredero Mohamed VI se dirigía a la nación mediante la televisión y radio pública marroquí, ya había comenzado una maquinaria logística de los medios de comunicación de España y de numerosos países del mundo. Los pocos corresponsales españoles acreditados en Marruecos ${ }^{1}$, -sólo una cadena de televisión: Canal Sur; de agencias informativas: la agencia EFE, y algunos periodistas de prensa como los corresponsales de El País o ABC- se encontraban desbordados de trabajo y se presagiaba un desembarco en Marruecos de decenas de periodistas españoles y extranjeros.

Para los enviados especiales comenzaba una odisea informativa, Marruecos es un país en vías de desarrollo, una cultura distinta a la europea, la religión, todo aderezado con la muerte del Rey y con una pregunta que circulaba por todas las 1 Ver Tabla de los corresponsales de los Medios de Comunicación españoles acreditados en Marruecos, según
la Embajada de España, Consejería de Prensa, Rabat, 1999. 
esferas marroquíes y mundiales: ¿Qué iba a pasar en Marruecos?. No debía ocurrir nada extraordinario al margen de los funerales y la sucesión en el trono.

Algunos de los periodistas que iban a Marruecos para cubrir la noticia era la primera vez que viajaban a este país, aunque los responsables de los medios intentaron en la medida de lo posible enviar a profesionales de la información que conocieran el país, o que hubiesen estado como mínimo en algún país árabe, la misión no era tan arriesgada como ir a una guerra, pero si se sabía que habría problemas de infraestructuras: desde mandar una crónica por satélite para televisión, o saber si iban a surgir problemas con la telefonía móvil para que los periodistas de radio pudieran enviar sus crónicas.

La muerte del Rey marroquí se había producido y comenzaban los reportajes del país, la retransmisión de los funerales, la sucesión, Jefes de Estado, por primera vez en la historia moderna de este país magrebí: Marruecos se iba a convertir en la capital mundial de la diplomacia. Desde la Exposición Universal del 92 de Sevilla, donde los Jefes de Estado y Reyes iban llegando a la capital andaluza coincidiendo con el día nacional de su país, ningún acontecimiento mundial iba a tener tanta repercusión periodística y social.

\section{CORRESPONSALES Y MEDIOS ESPAÑOLES}

EN MARRUECOS (1)

AGENCIA ESPAÑOLA DE NOTICIAS. EFE

FERNANDO CASARES

DIRECTOR

RABAT

PERIÓDICO EL PAÍS

SEMANARIO TRIBUNA DE ACTUALIDAD

PEDRO CANALES

CORRESPONSAL

RABAT

PERIÓDICO $A B C$

ENRIQUE SERBETO GABAS

CORRESPONSAL

RABAT

PERIÓDICOEL CORREO ESPAÑOL DEL PUEBLO VASCO

VIRGINIA IBAÑEZ

CORRESPONSAL

RABAT

CADENA COPE

JOSÉ LUIS PERCEBAL IBAÑEZ

CORRESPONSAL

\section{RABAT}


EL PERIÓDICO DE CATALUÑA

ANTONIO BAQUERO

CORRESPONSAL

\section{RABAT}

DIARIO EL MUNDO

JAVIER ESPINOSA

RABAT

CORRESPONSAL

LA VANGUARDIA

CRISTINA FERNÁNDEZ

RABAT

CORRESPONSAL

RADIO TELEVISIÓN ANDALUZA. RTVA (CANAL SUR)

MANUEL ARROYO DURÁNDELEGADO-CORRESPONSAL

RABAT

\section{La noticia del verano del 99}

Se iba a convertir en la noticia del fin de semana y de los siguientes días, y la del verano, pero no en el tradicional culebrón. Hassán II se encontraba enfermo desde hacía tiempo pero nadie esperaba lo peor de forma tan rápida y fulminante. Había comparecido el Rey marroquí en algunos actos la semana anterior a su fallecimiento, donde había presidido en París en los Campos Elíseos, un desfile militar, dentro del día nacional de Francia, el 14 de julio, junto al presidente galo Chirac. Nadie presagiaba lo que iba a ocurrir pocos días después en Marruecos. Pero la noche del jueves enfermó en su residencia veraniega a las afueras de Rabat.

La muerte del Rey de Marruecos en un fin de semana de verano aglutinó el centro informativo mundial: teletipos, programas especiales, reportajes, suplementos recordando a Hassán II, todo un espectáculo informativo sobre la figura de un rey muerto.

Tenía todos los condicionantes: verano, poca actividad informativa, Marruecos país africano exótico, desconocido, la muerte de un Rey en un país islámico cerca de Europa y vecino de España, la sucesión y la familia real con todo el protocolo y evidentemente el funeral por televisión retransmitido para todo el mundo, ¿qué medio de comunicación no quería estar en Marruecos?...

\section{Los enviados especiales a Marruecos}

El Ministerio de Comunicación de Marruecos se encargó de acreditar a unos 300 profesionales de la información que llegaron de todo el mundo para cubrir la noticia. España y Francia eran los que contaban con mayor representación, aunque había periodistas desde Camerún hasta de Estados Unidos, de Canadá 
o China. El domingo eran los funerales y la llegada de un centenar de Jefes de Estado, Reyes o Príncipes. A los 1200 profesionales de los medios de comunicación locales había que unir la masiva llegada a Rabat de periodistas extranjeros. La veintena de diarios marroquíes, sus dos canales de televisión T.V.M. y la $2 \mathrm{M}$, más la radio nacional marroquí y Radio Mediterráneo, la principal cadena privada de radio, junto con la M.A.P, la agencia de noticias de Marruecos (Magreb Agency Press) constituyen el grueso de los medios de información marroquíes.

Las televisiones extranjeras contaron con los servicios de las unidades móviles desplazadas para poder enviar las imágenes junto al esfuerzo que hizo la televisión marroquí que dio servicio a varias cadenas para que pudieran enviar sus crónicas. La retransmisión de los funerales se hicieron con cámaras de la televisión marroquí y cada país recogía la señal.

Las emisoras de radio empleaban sus teléfonos móviles y los periódicos internacionales recibían las crónicas y fotografías también por satélite, fax o teléfonos. En la M.A.P. se instaló un centro de prensa para poder enviar crónicas y aunque no se podían hacer llamadas internacionales si había monitores de televisión para seguir los funerales y se podía usar como recepción de llamadas sobre todo para las emisoras de radio.

Se instalaron un par de vehículos para que los cámaras internacionales pudieran seguir el cortejo fúnebre por las calles de Rabat, entre el Palacio Real y el Mausoleo. Había cierto orden con el control de la policía marroquí. La radio fue el medio de comuncación que pudo seguir mejor los acontecimientos con cierta autonomía gracias a la telefonía móvil. Andalucía Información, la emisora de información de Canal Sur Radio era la primera vez que cubría en directo un acontecimiento mundial e informaba cada media hora a todos los andaluces.

Todas las cadenas de radio españolas habían enviado corresponsales, algunas televisiones autonómicas españolas también se desplazaron, como Canal Nou, La Televisión Autonómica de Valencia, o TeleMadrid y evidentemente Canal Sur Televisión. Había un centenar de periodistas españoles que fueron como enviados especiales a Marruecos.

En la tarde noche del caluroso viernes 23 de julio, ningún responsable de un medio de comuncación marroquí se atrevía a "moverse" si no era con los comunicados oficiales o con una información de la M.A.P. o la T.V.M. Cuando Mohamed VI salió en una alocución en la radiotelevisión marroquí ya era muy tarde para la mayoría de los diarios. El problema de la distribución y la impresión hacen que la prensa diaria cierre edición como muy tarde al filo de las 7 , o las 8 , las 9 ya sería tarde. Todos los diarios sólo incluyeron la noticia de la muerte de Hassán II en la portada y se desarrolló la información en alguna página interior en algunos casos, pero no pudieron hacer una edición especial salvo Le Matin del importante Grupo Maroc Soir que se edita en francés, 
periódico monárquico de los más leídos, que sí la hizo, con 8 páginas en lugar de las 16 habituales ${ }^{2}$

L'Opinon, del Partido del Istiqlal, sólo pudo cambiar la portada y colocó en la última página una galería de fotografías. En el interior se comprueba que no hay cambios y el periódico, ya que no era posible que al día siguiente llegara a los quioscos a tiempo. Sale la parrilla de la programación prevista de la televisión pública del día siguiente cuando ya estaba emitiendo la lectura de los versículos del Corán ${ }^{3}$.

Pero a otros medios de prensa escritos no les dio tiempo a reaccionar y aunque son semanarios que suelen salir los viernes, justo el día en que murió Hassán II, el problema de las rotativas en Marruecos, sólo existen un par de ellas importantes, hizo imposible que los semanarios Maroc Hebdo International y La Vie Economique cambiaran al menos sus portadas ${ }^{4}$.

La información de la muerte de los funerales se repetía en toda prensa. El diario Almaghrib (del Partido conservador R.N.I. -Asamblea Nacional Independiente-), el 27 de julio, varios días después de la muerte, aún continuaba publicando fotos de las exequias, como el resto de los medios marroquíes ${ }^{5}$.

Los 40 días de luto oficial decretados en Marruecos iban, desde que los periódicos no editaban en color, sólo en blanco y negro en señal de luto, incluido los logotipos de colores que se cambiaron al negro, hasta los versículos del Corán que se repetían día y noche en la radio y televisión. Poco a poco a medida que iban pasando los días se iban incluyendo más informativos, más documentales o películas de temas religiosos por citar alguna programación. También en la $2 \mathrm{M}$, la segunda cadena marroquí que se caracteriza por una programación muy europea, similar a Canal Plus.

\section{La mañana}

El Grupo Maroc Soir con sede en Casablanca cuenta con 3 diarios: La Mañana en español el único diario en lengua española de todo Marruecos, Le Matin en francés y Sáhara en árabe, además pública un semanario y tiene las rotativas más importantes del país donde publican varios diarios y semanarios.

La Mañana, creado en 1990, uno de los diarios más pequeños de Marruecos con una tirada media de unos 3.000 ejemplares cuando la media nacional se cifra de unos 25.000 a 40.000 ejemplares cada día, dentro de su modestia periodística

2 A. D. $\mathrm{N}^{\circ} 1$, Portada de Le Matin, 24 de Julio de 1999

3 A. D. No 2 Potada de L'Opinion, 24 de Julio de 1999.

4 A. D. o 3 y 4 , Portada de los semanarios Maroc Hebdo International y La Vie Economique $(23$ a 29 de Julio de 1999). En Maroc Hebe Internationac de Julio de 1999). En Maroc Hebdo International se publicaba en portada una noticia sobre la aparición de un cadáver de una marroquí en el aeropuerto de Londres y en la Vie Economique insertó en la primera página 5 A. D. N ${ }^{\circ}$, Portada de Almaghrib del día 27 de Julio de 1999. 
pudo sacar igualmente una edición especial, como su compañero del mismo grupo Le Matin en lengua francesa.

Sus escasos 6 profesionales de la información dirigidos por el periodista (profesor de español Mohamed Lachiri) fueron de los pocos medios privilegiados al contar con rotativa propia que les permitió poder sacar la noticia de la muerte de Hassán II no sólo en la portada sino en páginas interiores. Trabajaron hasta la madrugada, pero su diario, habitualmente de 8 páginas, salió con 4 en una edición especial ${ }^{6}$.

Este periódico en español nunca sale con una edición el lunes, porque sus pocos medios de infraestructura y personal no se lo permiten. La edición que elabora el sábado, es la del domingo y lunes. Pero los acontecimientos hicieron que la redacción trabajara por primera vez un domingo, el día 25 de julio cuando se celebraron los funerales en Rabat. Se publicó una edición especial el lunes donde se recogían los actos que se habían celebrado en Rabat. Se recogía por primera vez un texto en árabe en este periódico en español que tiene su logotipo en color verde pero se cambió por el luto al color negro. En la portada se podía leer en árabe: "Cuando la persona muere el alma sube en paz con Dios"7.

\section{Crónica personal de un enviado especial}

La muerte de un Rey no llega a diario para un periodista. Un acontecimiento mundial fue la muerte de Hassán II que pude "cubrir" para mi emisora de radio Canal Sur Radio y su canal de noticias Andalucía Información. El conocimiento que tengo del país marroquí me permitió moverme con facilidad y comodidad por las calles de Rabat el día 25 de julio de 1999, una jornada que ningún periodista de los que estuvieron en Marruecos olvidará jamás. Las tranquilas calles de Rabat, una ciudad, capitalina, sin agobios como Casablanca, se atestaron de marroquíes llegados de todos los poblados y pueblos del país para despedir a su Rey, a su Príncipe de los Creyentes.

Por la mañana, el domingo en el aeropuerto de Rabat, llegaron las primeras autoridades mundiales y jamás un periodista se pudo acercar tanto a Clinton y Hilary, la pareja estaba a tiro de foto de primer plano sin dificultad, la policía marroquí dejó trabajar a la prensa internacional y colaboró para que pudieran hacer bien su trabajo. Quienes tenían los problemas eran los servicios de seguridad de cada comitiva.

El colorido de los jefes de estado africanos, con sus trajes estampados, contrastaba con las lágrimas de Juan Carlos captadas por todas los medios. El desfile aéreo se hizo corto, nunca un aeropuerto había tenido tanto movimiento. El

6 A. D. No 6 Portada de La Mañana, sábado 24 de Julio de 1999

7 A. D. N 7 Portada de La Mañana, lunes 26 de Julio de 1999, ejemplar histórico, nunca había salido una edición un lunes en los diez años que tiene este diario marroquí que se edita en lengua española. 
ruido de los motores se mezclaba a veces con los himnos o acordes nacionales de algún país diminuto como Burkina Faso. Los aviones se agolpaban para aterrizar mientras olía a té en el Pabellón Real del Aeropuerto donde era fácil hablar con los ministros marroquíes, varios hablan español.

Las crónicas para la radio con sonido real de aviones de fondo no podían ser más expresivas desde el lugar de la noticia: Clinton, Juan Carlos, Aznar, a un par de metros.

Por la tarde, el calor pegajoso en las calles, ante la mirada atenta de miles de policías que hacían un pasillo entre la salida y la llegada de la comitiva fúnebre. Había que buscar un lugar estratégico y no moverse. La Puerta del Palacio Real de donde saldrían los restos mortales de Hassán II era un buen lugar. Las vallas no aguantaban a los dos millones de marroquíes que se agolpaban en las calles de Rabat. Niños, adolescentes, mujeres, se iban desmayando por el calor y la falta de oxígeno, las vallas se caían y la policía empujaba las vallas hacia atrás y todavía no había comenzado el paso del cortejo. El ruido y los cánticos llegaban al corazón de todos los presentes: "Adiós Hassán, Mohamed tú eres el Rey", era alguno de ellos que se podían escuchar.

Cuando pasó el cortejo, los jóvenes se caían de los árboles, y la muchedumbre empujaba con más fuerza, un buen cinturón policial rodeaba al rey muerto y al heredero, pero un pueblo enloquecido achuchaba y empujaba, se aceleró el paso y desde Clinton al último asistente o caminabas hacia delante deprisa o te aplastaba la muchedumbre. En estas condiciones mandar crónicas para la radio en directo, cuanto menos es complicado, pero un árbol me salvó de tanta explosión popular. Me coloqué detrás de tan ilustre especie arbórea con un buen tronco, teléfono en mano, mirando al frente, el tronco me resguardaba, mientras intentaba narrar para la radio, mientras miles de personas cruzaban a mi lado, a derecha e izquierda a gran velocidad, mientras oía el zumbido de su paso...

El tópico de que la telefonía móvil para la radio ha sido el gran invento que permite estar en cualquier lugar y contar el acontecimiento en directo tiene su máxima expresión en estos acontecimientos mundiales que vivimos un grupo de periodistas españoles en el verano del 99 en Marruecos. 


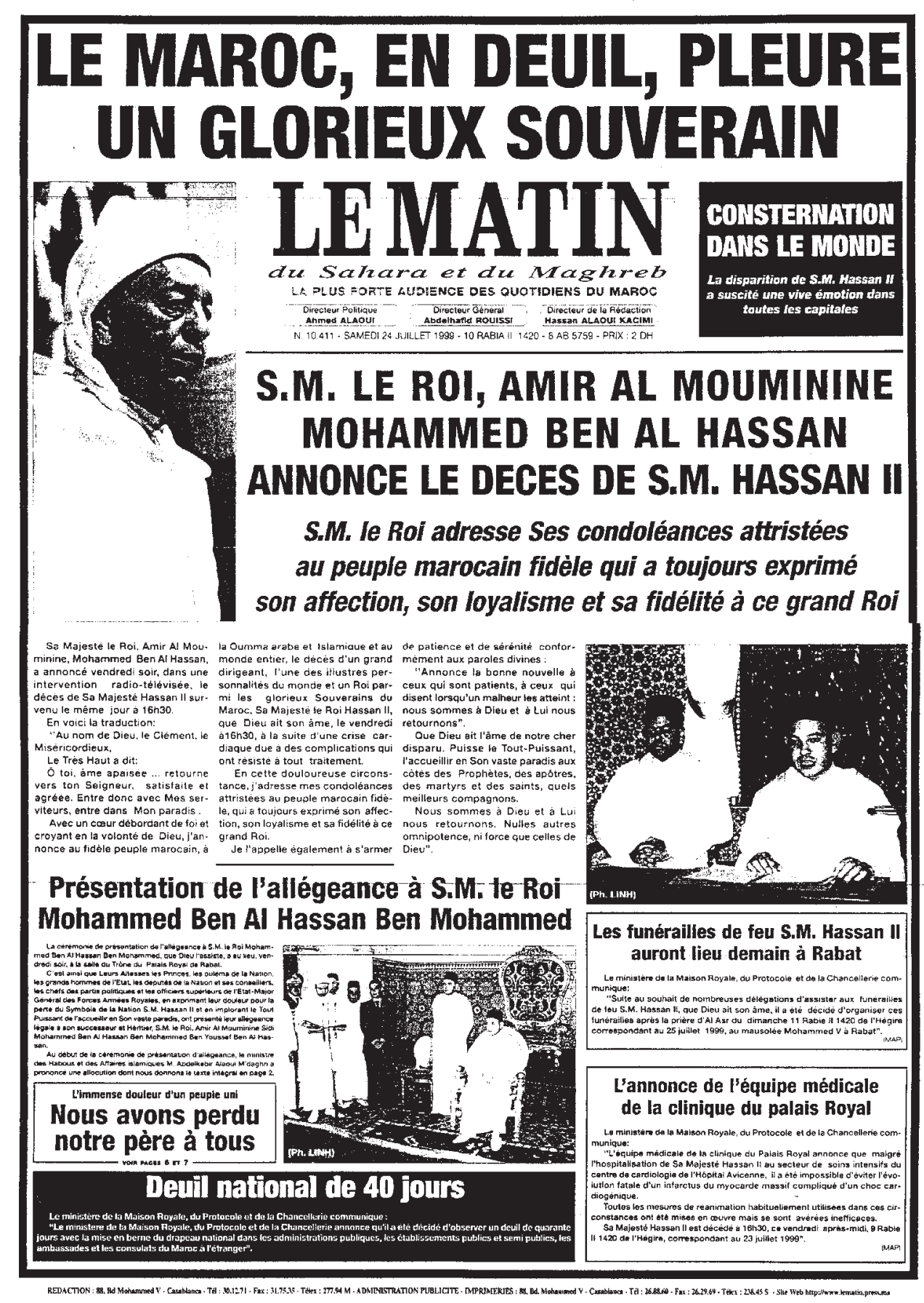




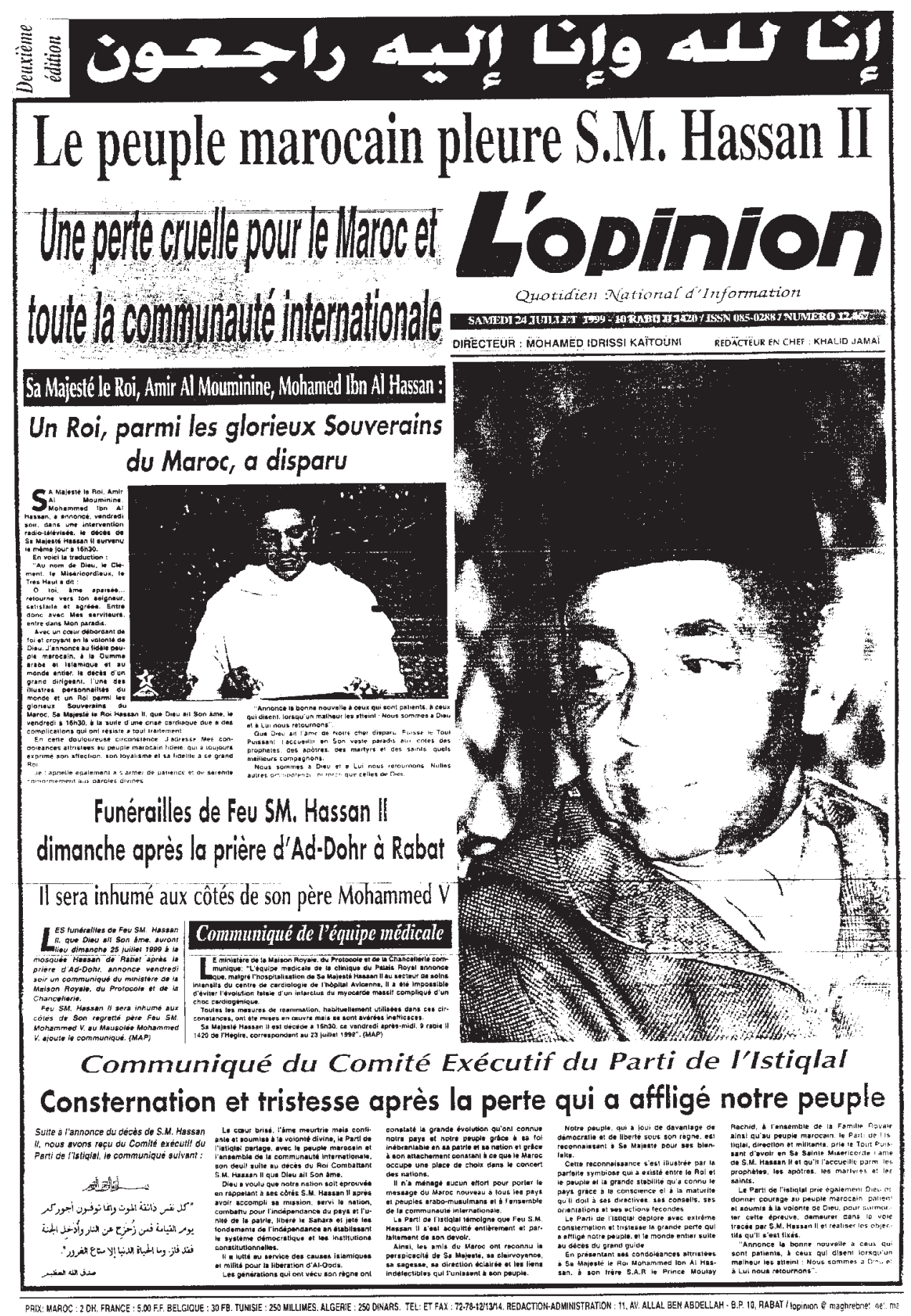




\section{DANSUN CLIMAT DE PIETE, DERECUELLEMENTET DEFORTEEMOTION}

\section{LE PEUPLE MAROCAIN \\ ET LES DIRIGEANTS DU MONDE \\ ONT ACCOMPAGNE FEU \\ S.M. HASSAN II A SA DERNIERE}

DEMEURE
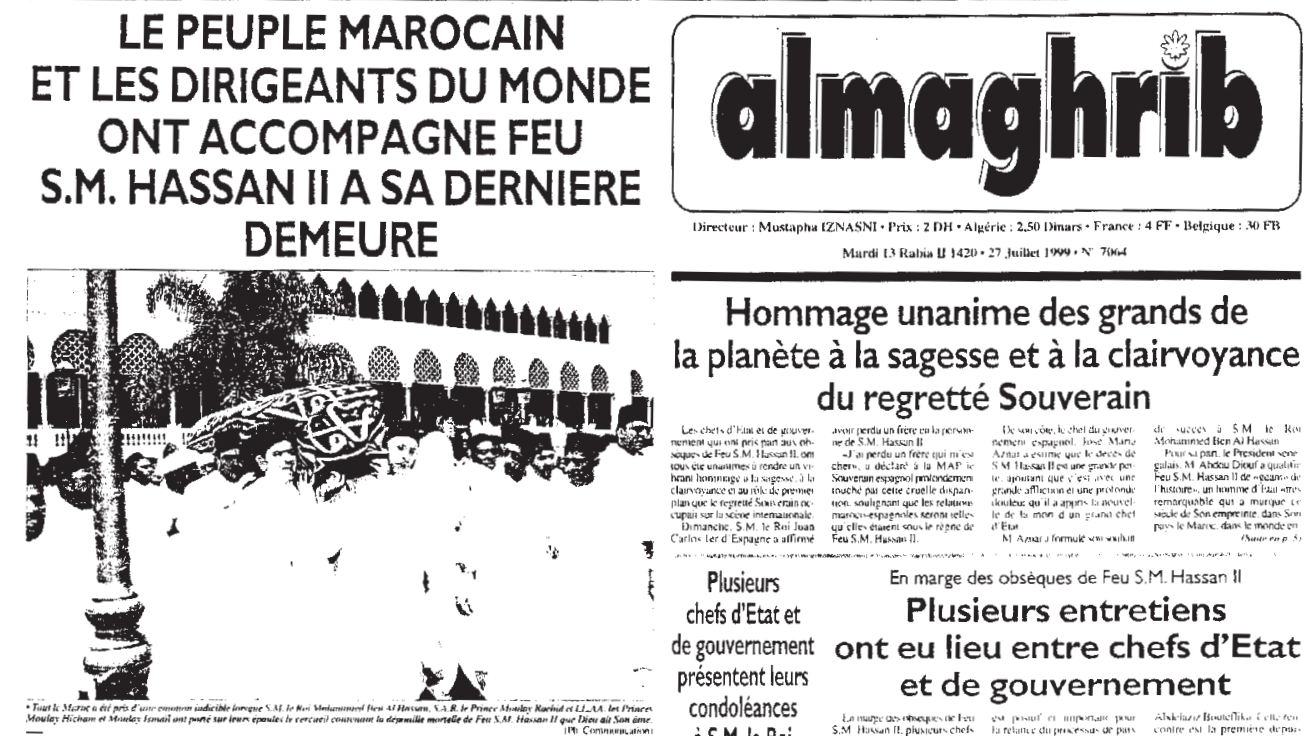

Hommage unanime des grands de la planète à la sagesse et à la clairvoyance

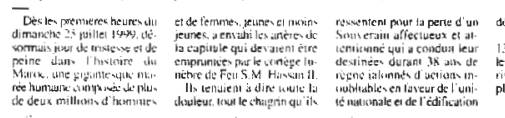

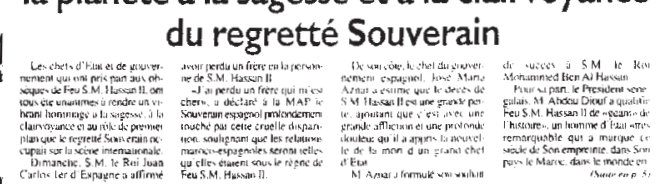

? Plusieurs cheis d'Etatet de gouvernement
presentent leurs

Plusieurs entretiens

presententlears
condoleances

eu lieu entre chefs d'Etat

Message du Presisiderr Bouceelika a S.M. Mothanmed Ben Al Hass

à œuvrer avec Votre Majesté la main

dans la main pour la réalisation des

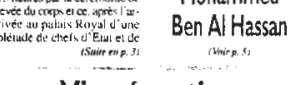

Yive émotion chez la communauté aspirations de nos peuples" et de gouvernement

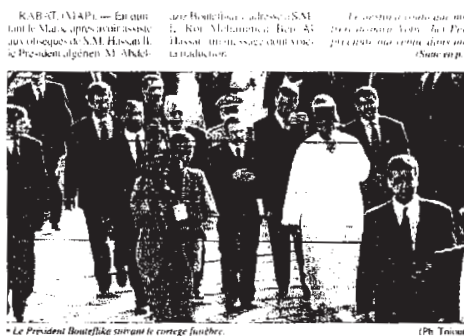
marocaine à l'étranger

UN SALUT A L'ACTION INLASSABL MENEE EN FAVEUR DU MAROC ET DES CAUSES DE LA PAIX ET

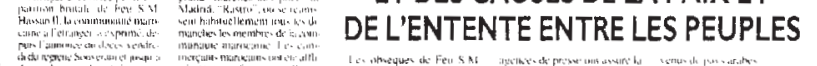

Le Président Maroc-Algérie
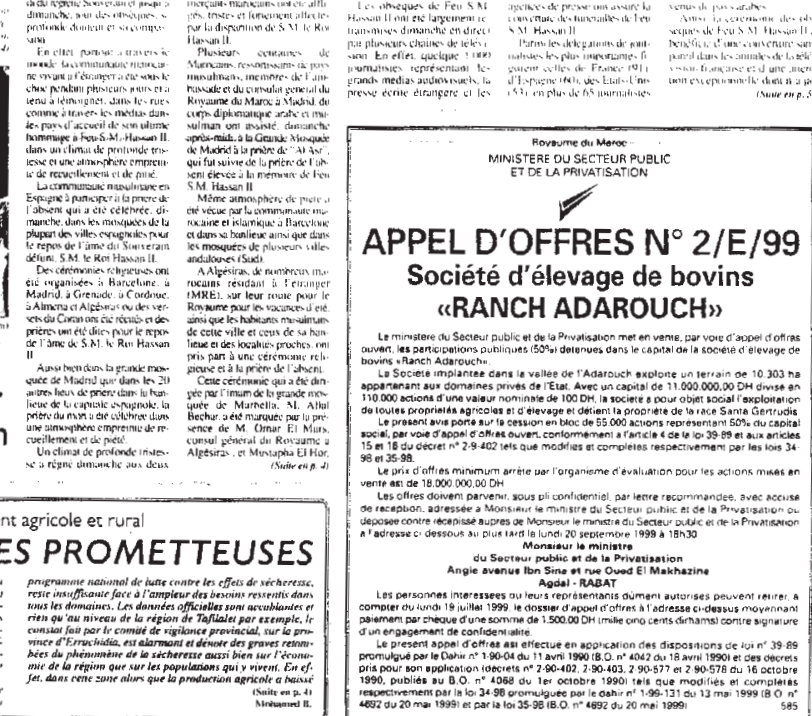
un rapprochement maroco-algérien 


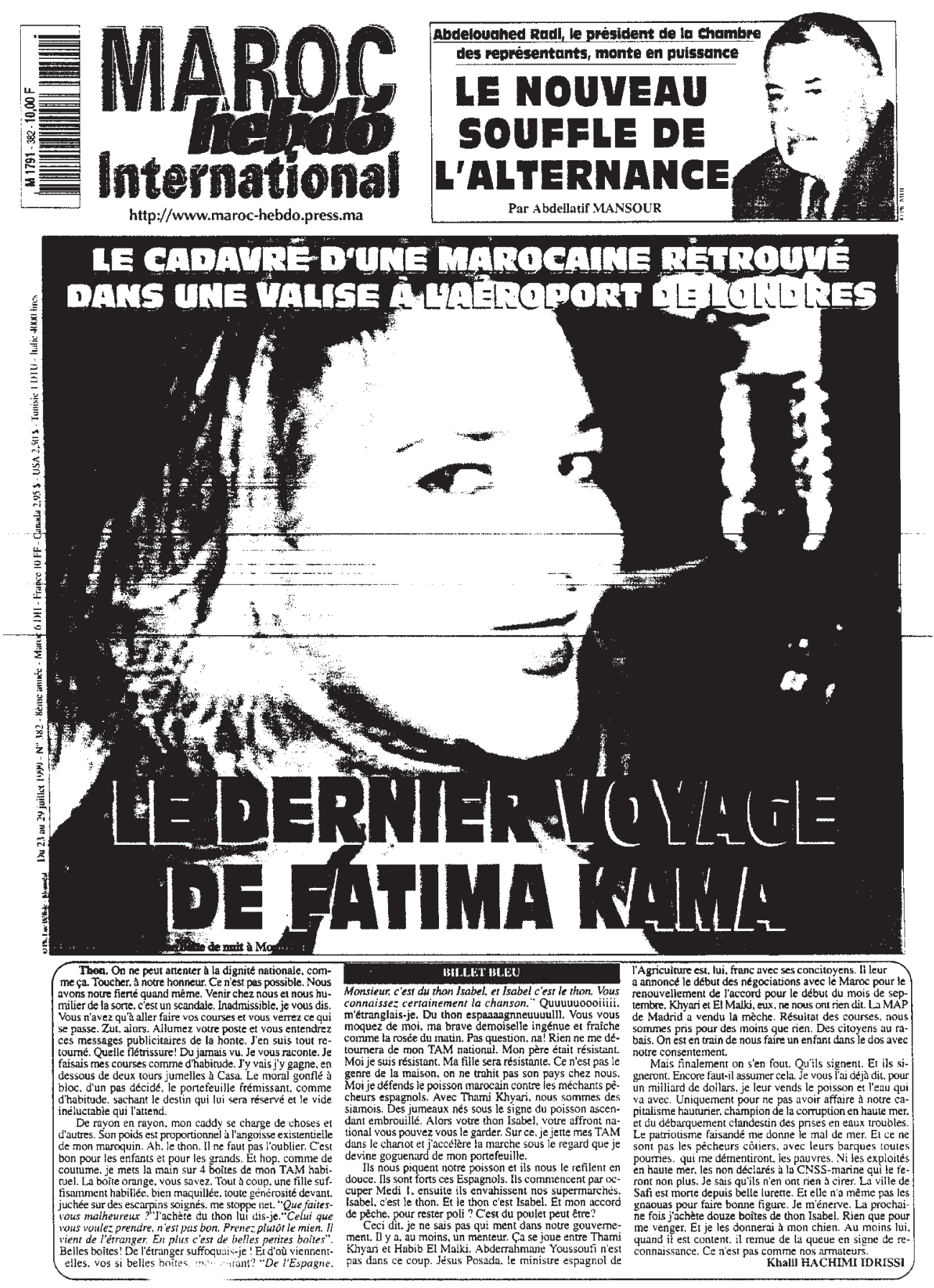




\section{MARRUECOS ILORA LA PARDIDA DE UN GRAN REY}
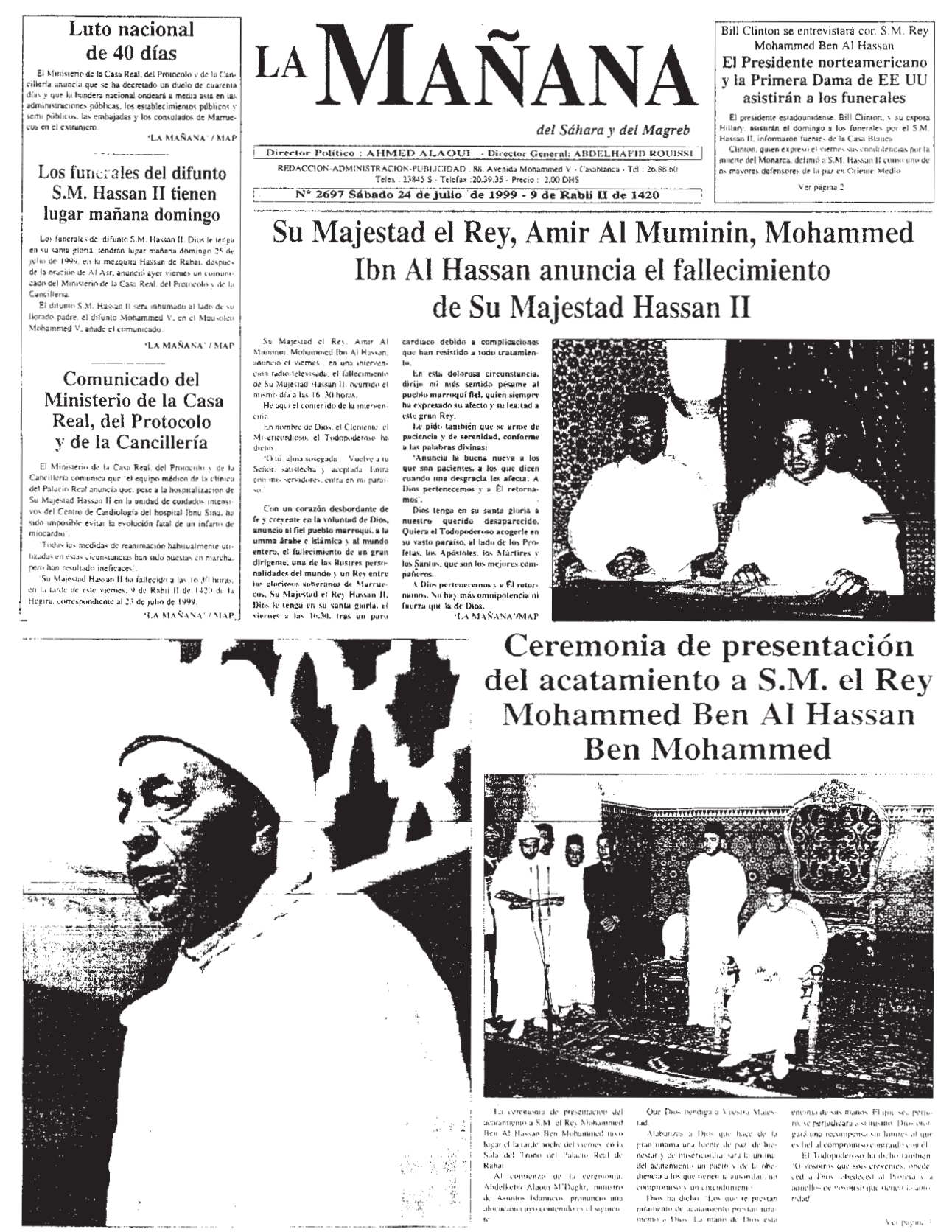


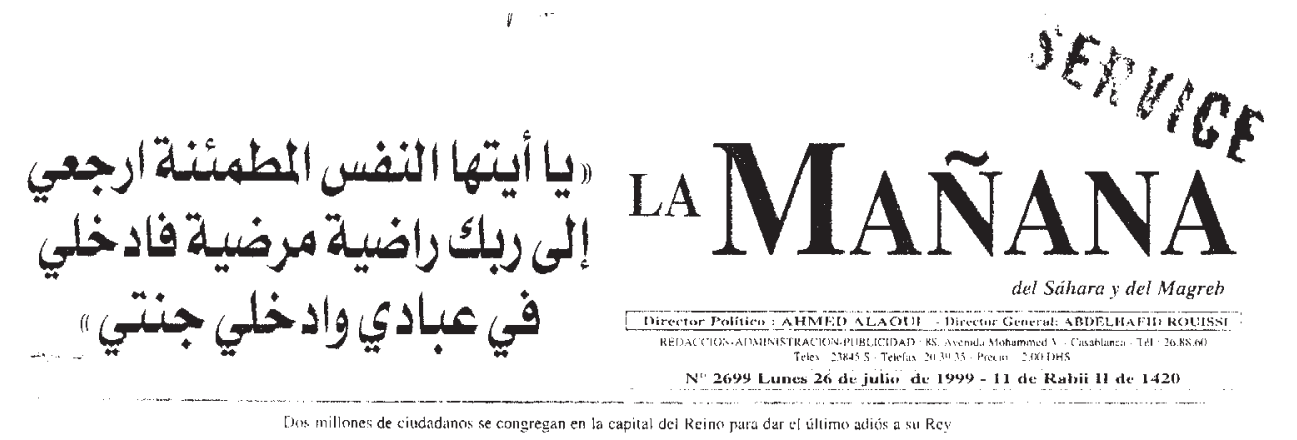

S.M. el Rey Mohammed Ibn Al Hassan preside los funerales del difunto S.M. Hassan II Unas 70 delegaciones extranjeras representantes de paises hermanos y amigos

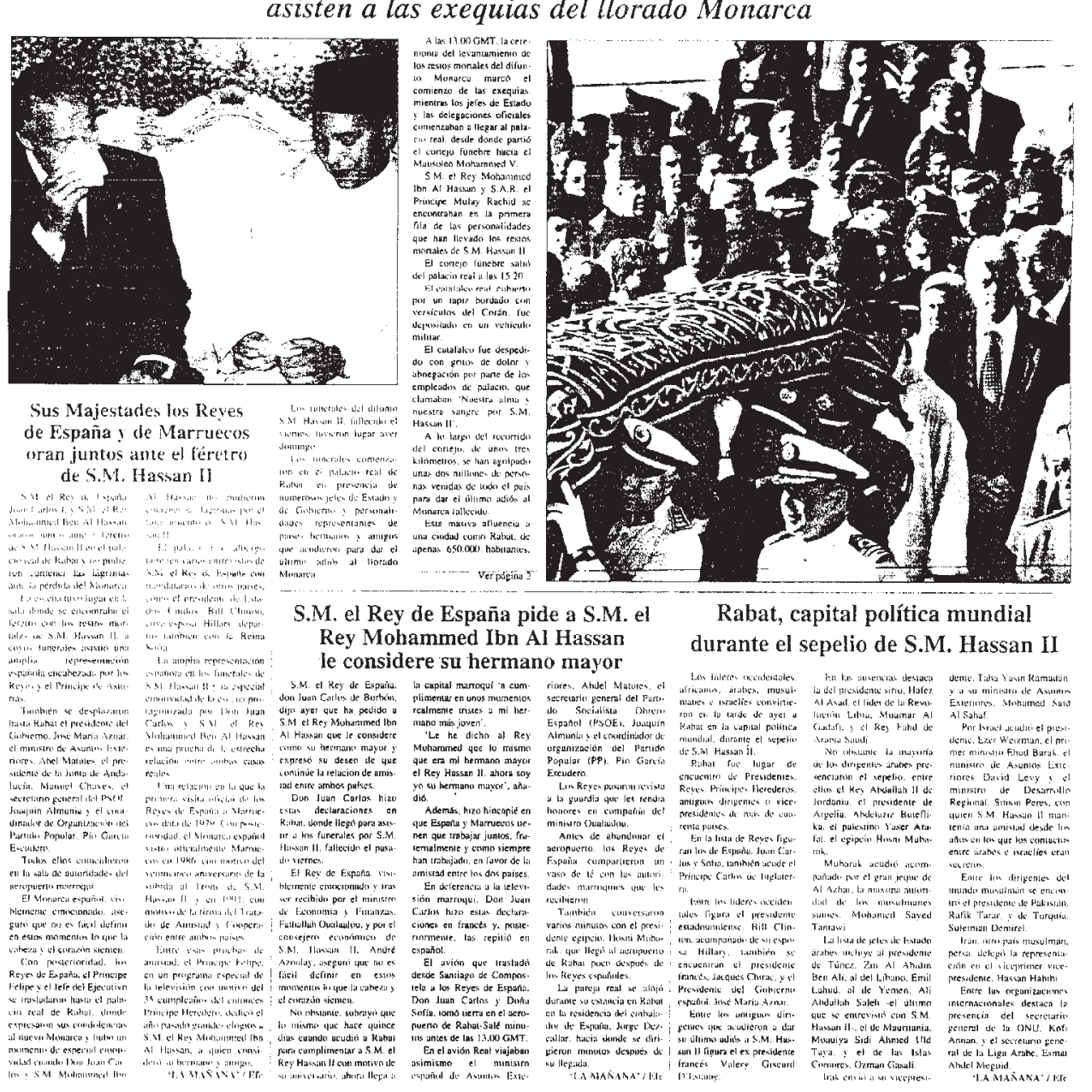

